\title{
A Student Parent Assistance Pilot Program for Incoming Associate-Degree Students
}

\author{
John Hudesman, Nicholas Millet, and Dorie Clay
}

This Student Parent Assistance Pilot Program engaged family members to support their students in adapting to the academic challenges of entering college. Materials were constructed so that family members did not have to be knowledgeable in the course content in order to assist their students. Outcomes indicated that participating students and their family members had a more positive view of the program than did a non-participating comparison student group. A student vignette is used to illustrate the students' positive view of the program.

Families of incoming college students are often enthusiastic about their students' upcoming college experience. They view college as a crucial opportunity for their children to gain the knowledge and skills necessary to succeed. Unfortunately, many first-generation and financially disadvantaged college students may not have the benefit of such parental enthusiasm, which, in turn, can be a significant deterrent to the student's success. York-Anderson (1992) identified the lack of family support as one reason why these students fail to graduate. Similarly, Engle and Tinto (2008) found that these students are nearly four times more likely to leave college after their first year than other students.

To address this issue, many colleges have implemented a variety of studentparent orientation programs; however, the parents' role in these programs is generally restricted, e.g., how to file financial assistance applications or how not to be a "helicopter parent" (Wolf, Sax, \& Harper, 2009). By contrast, we will describe a demonstration program in which family members can broaden their role and academically support their students.

One impasse to implementing such a program is the philosophical divide between those educators who believe that when students enter college they should

John Hudesman (jhudesman@gc.cuny.edu) is an Adjunct Professor with the Percy Ellis Sutton SEEK Program, New York City College of Technology and a Senior Principal Investigator at the Center for Advanced Study in Education at the CUNY Graduate School and University Center.

Nicholas Millet (NMillet@citytech.cuny.edu) is a counselor with the Percy Ellis Sutton SEEK Program at New York City College of Technology.

Dorie B. Clay (dclay@citytech.cuny.edu) is the Director of the Percy Ellis Sutton SEEK Program at New York City College of Technology.

The authors would like to acknowledge the contribution made by Ms. Altagracia Ramirez in working with the study participants. 
be free to make their own choices, even if it means stumbling along the way (Coburn \& Treger, 2003). By contrast, other educators have concluded that some students, specifically those who are the first in their families to attend college, still require support from their families. For example, Gloria et al. (2005) concluded that family support has a positive influence on the persistence of first generation students, and Turner et al. (2009) found that college students who reported more interactions with their families also had higher GPAs.

It is against this backdrop that we have designed a Student Parent Assistance Pilot Program (SPAPP) that takes into account the needs of incoming students as well as what can reasonably be expected from family members, especially when many of them have very little or no college experience. The first challenge to implementing such a program is the students' academic backgrounds. Many students who enter associate-degree programs have lower levels of academic preparation and fewer positive school experiences, which can make it difficult for them to engage with the various programs offered by the college. On a positive note, many of these same students still have strong ties to their families, especially to mothers and grandmothers. Another challenge to implementing the SPAPP is that many of the students' relatives do not have their own set of college experiences, and even if they do have some college background, they can hardly be expected to remember specific good academic practices from years ago. Based on these considerations, the SPAPP sought to explore how families might assist their students as part of an academic summer transition program.

\section{Method}

\section{The Setting and the Participants}

The SPAPP was implemented at an urban commuter college with an enrollment of more than 16,000 students. The college offers some of its academically under-prepared and economically disadvantaged incoming students an opportunity to participate in a higher education opportunity program which includes an orientation program, counseling, and developmental or credit level course work. On average, the program admits 180 female and 220 male students per year, and over $90 \%$ are minority students.

Thirty students and their family members were recruited for this pilot program. These students and their family members were informed about the SPAPP as part of a general orientation session. Program participants included 16 male students and 14 female students. There were 26 female family members, of whom 23 were mothers. There were also four male family member participants, all of whom were fathers. The families represented a variety of different national origins and spoke a variety of languages at home. All students had to sign an agreement that allowed their family members to participate. 


\section{Program Materials}

A crucial SPAPP element was the development of program materials that would facilitate positive communication between students and their family members. It was understood that these materials would have to be useable by family members who had little or no college experience. Toward this end, we created three types of materials: 1) a modified syllabus where assignments, quizzes, and examinations are highlighted and circled; 2) a monthly calendar on which the student and family member import and track items from the syllabus; and 3) a menu of discussion questions that could be used by family members to facilitate conversations about the student's classroom experience. The following discussion questions were used as a guideline by family members:

- How was your commute?

- Did you make it to class on time?

- Did you feel you understood the lesson?

- How did you do on your last test?

- When is your next test?

- What might you do to improve the next time?

Family members were asked to limit the number of questions they ask their students at any one time.

\section{Procedure}

A co-author (NM) and an intern (AR) met with the students biweekly. During the first meeting, they raised the following discussion questions:

- Did you receive a syllabus in your class?

- Tell me about the conversation you had with your family member about your syllabus.

- How helpful was it for you to enter important dates from your syllabus on to the calendar with your parent?

- Was your family member involved with your academic progress in high school?

- How would you expect your family member to help/support you during these summer classes as you prepare for college?

Subsequent interviews with the students addressed the following questions:

- Describe how your family member has been involved during your summer experience since our last meeting.

- Would you describe their involvement as helpful?

- How you would improve their involvement in the future? 
In addition, biweekly semi-structured phone interviews were conducted with family members. The topics discussed with the family members during the first contact paralleled those topics discussed with their student. During the follow-up telephone discussions, parents were asked

- Tell me about the conversations that you had with your student regarding their progress in the course.

- How have you helped your students so far this week?

- What plan do you have for your next discussion with your student?

During the last week of the program, students and family members were asked to complete a three-question survey to assess their overall experience with their program. Students were also asked to summarize their program experiences.

\section{Results}

We collected two types of program data: 1) survey data collected from the SPAPP students, their family members, and a non-participating comparison group of students and 2) anecdotal program summaries from the participating students.

Survey Responses

TABLE 1

\section{Mean Scores, ANOVA Values, and Multiple Comparisons for the Survey Questions}

\begin{tabular}{|c|c|c|c|c|}
\hline \multirow[b]{3}{*}{ Group (N) } & \multicolumn{3}{|c|}{ Survey Question } & \multirow{3}{*}{$\begin{array}{c}\text { Total } \\
\text { Mean Score }\end{array}$} \\
\hline & 1 & 2 & 3 & \\
\hline & Mean Score & \multicolumn{2}{|c|}{ Mean ScoreMean Score } & \\
\hline Student Participants (23) & $5.61^{2,3}$ & $5.70^{3}$ & $6.04^{3}$ & $5.78^{2,3}$ \\
\hline Parents & $6.88^{1,3}$ & $6.30^{3}$ & $6.76^{3}$ & $6.65^{1,3}$ \\
\hline Comparison Group (40) & $4.20^{1,2}$ & $4.40^{1,2}$ & $4.60^{1,2}$ & $4.40^{1,2}$ \\
\hline ANOVA (F value) & 20.38 & 26.82 & 25.13 & 68.04 \\
\hline
\end{tabular}

1,2,3 Scheffé Multiple Comparisons significant at the $\mathrm{p}<.05$ level or less 
Three parallel forms of a three-question survey were administered to program students, their family members, and a comparison group of students who were enrolled in the same courses as the SPAPP students. The general question format for the three surveys was Question 1: Having a parent or other adult involved as part of the summer program is a (bad) (good) idea; Question 2: Having a parent or other adult be part of the summer program definitely (lowers) (improves) grades; and Question 3: Having a parent or other adult be a part of the summer program definitely (does not) (does) encourage me. All survey responses were formatted using a seven point Likert scale. The data in Table 1 summarizes the survey responses.

The data indicate that participating students and their family members responded more favorably than non-participating students to each of the three survey questions as well as to the total score for all three survey questions. These results indicate that the program participants come away from the experience with more favorable impressions than a comparison group of non-participating students.

\section{An Anecdotal Report}

In a series of meetings with the counselor, participating students were asked to summarize their reactions to the program. What follows is a typical student's response.

Lorenzo's initial approach to his developmental mathematics course work resulted in low quiz scores. He attributed his poor performance to what he acknowledged as "overconfidence" and "poor study habits." His rationale was that the material seemed familiar from high school mathematics, and he had a lot on his plate. By contrast, Lorenzo's mother was enthusiastic about the SPAPP and regularly reviewed the program discussion questions with him. He acknowledged that, initially, he was not pleased with her inquiries, considering them a nuisance; however, over the course of the program, Lorenzo began to welcome her participation and found himself developing better study habits. He reported, "At first, I didn't like it because I do math all day in school, and when I go home, I don't want any more math. But now, I don't mind because I'm doing better; I'm studying more now than before." Lorenzo passed the course exit examination by a wide margin.

\section{Discussion}

The project yielded some good news and clarified some program challenges. We found that program participants, both students and their family members, consistently had a more positive view of the SPAPP than a comparison group of students who did not participate in the program. These positive survey responses are supported by the students' anecdotal reports of their program experiences. As mentioned, most students indicated that, while they were initially skeptical about 
having family members participate, they came to see the value of such support.

This pilot program also highlights some challenges that must be addressed when developing and implementing future programs. For example, the overwhelming majority of family members who assisted program students were female. It would be desirable if we could involve more male family members in the program.

There are also a variety of procedural issues that should be addressed. These include, but are certainly not limited to, counselors connecting with families who don't speak English, being able to make contact with family members whose work schedules vary widely, and making ongoing contact with students at a commuter college who tend to leave the campus immediately after their classes.

Despite the previously mentioned significant challenges, we believe that it is worthwhile to continue to explore how families can academically support students in their transition to college.

\section{References}

Coburn, K. L., \& Treger, M. L. (2003). Letting go: A parents' guide to understanding the college years (4th ed). New York, NY: Harper Collins Publishers.

Engle, J., \& Tinto, V. (2008). Moving beyond access: College success for low-income, first generation student. Washington D.C.: The Pell Institute for the Study of Opportunity in Higher Education.

Gloria, A. M., Castellanos, J., \& Rosales, R. (2005). An examination of academic non-persistence decisions of Latina undergraduates. Hispanic Journal of Behavioral Sciences, 27, 202-223.

Turner, E., Chandler, M., \& Heffer, R. W. (2009). The influence of parenting styles, achievement, and self-efficacy on academic performance in college students. Journal of College Student Development, 50(3), 337-346.

Wolf, D. S., Sax, L. J., \& Harper, E. (2009). Parental engagement and contact in the academic lives of college students. NASPA Journal, 46(2), 328-329.

York-Anderson, D. C., \& Bowman, S., L. (1992). Assessing the college knowledge of first-generation and second-generation college students. Journal of College Student Development, 32, 116-122. 